\title{
PÓS-FORDISMO E REFLEXOS NOS CONTRATOS DE TRABALHO
}

\section{Murilo Carvalho Sampaio Oliveira}

Advogado trabalhista e assessor jurídico de sindicatos profissionais em Salvador-BA, especialista em Direito do Trabalho pela Fundação Faculdade de Direito-UFBA, Mestrando em Direito Privado pela UFBA, Professor substituto de Direito do Trabalho da UFBA e da Faculdade de Ciências e Tecnologias - FTC.

e-mail: murilosampaio@yahoo.com.br

RESUMO: O trabalho analisa os efeitos das mudanças econômicas e técnicas provenientes da organização toyotista e da reestruturação produtiva no contrato de trabalho. Trata-se de caracterizar tais fenômenos e seus reflexos no Direito Laboral como ensejadores da crise do emprego. Identificar-se-á a flexibilização, precarização e terceirização como estratégias das relações pós-fordistas de ataque ao contrato de trabalho. Ao final, apresentar-se-á algumas conclusões e indagações que clamam pela necessidade de se repensar o Direito do Trabalho sobo viés do princípio da dignidade humana e da proteção ao hipossuficiente.

PALAVRAS-CHAVE: Novas relações de trabalho; crise do emprego; perspectivas para o Direito do Trabalho. 


\section{PÓS-FORDISMO ${ }^{1}$ E REFLEXOS NOS CONTRATOS DE TRABALHO}

\section{PRECEITOS}

\section{Operário em Construção.}

\section{$(\ldots)$}

Dar-te-ei todo esse poder

E a sua satisfação

Porque a mim foi entregue

$E$ dou-o a quem bem quiser.

Dou-te tempo de lazer

Dou-te tempo de mulher

Portanto, tudo o que vês

Será teu se me adorares

$E$, ainda, se abandonares

o que te faz dizer não.

E o operário disse: Não!

Loucura! - gritou o patrão

Não vês o que te dou eu?

Mentira! Disse o operário

Não pode dar-me o que é meu.

(...)

Vinícius de Moraes.

1 Utilizaremos o termo pós-fordismo como expressão caracterizadora das formas de organização produtiva advindas da crise do fordismo-taylorismo, combinado com os inovações da Terceira Revolução Industrial (microeletrônica) e nova engenharia produtiva da empresa (reestruturação produtiva). 
O mundo do trabalho contemporâneo, mesmo que complexo e heterogêneo, revive cotidianamente a situação narrada poeticamente por Vinicius de Moraes. A automação e a nova organização produtiva estabeleceram novas formas de execução do trabalho, inclusive utilizando-se de novos contratos de trabalho distintos da relação empregatícia ou mesmo mediante um contrato de emprego "flexível" e adaptado ao contexto atual. Não obstante, o operário em construção é revivido dia após dia na fábrica toyotista, pois o trabalhador prossegue empobrecido e em condições de trabalho piores do que na era fordista e taylorista ${ }^{2}$.

Por mais paradoxal que seja, o desenvolvimento do trabalho, particularmente após a Terceira Revolução Industrial, não tem importando em um desenvolvimento ou melhora das condições de trabalho. Em simplória análise histórica, o trabalho tem significado a libertação do homem, ao ponto de Domenico de Masi afirmar a existência de:

uma sucessão de fases liberatórias: a que vai desde as origens até a Idade Média trouxe a progressiva libertação da escravatura; a que vai da Idade Média até a primeira metade do século $X X$ trouxe a progressiva libertação da fadiga; a que teve início a partir da Segunda Guerra Mundial e na qual vivemos hoje visa à libertação do trabalho. (1999, p. 8) (grifo nosso)

Entretanto, os modos atuais de trabalhar não têm assegurado ao homem os meios de obter uma sobrevivência digna, a exceção duma pequena minoria de trabalhadores altamente especializados que se situam noutro patamar nas relações de trabalho, podendo exigir condições melhores de trabalho. Nesse sentido, os trabalhadores, incluindo aqueles abrangidos pela parassubordinação, permanecem em situação de aviltamento, carecendo ainda de um sistema jurídico protetivo.

O presente trabalho objetiva analisar os efeitos no contrato de trabalho das mudanças econômicas e técnicas provenientes da organização toyotista e da reestruturação produtiva. Trata-se de caracterizar tais fenômenos e seus reflexos no Direito Laboral, notadamente a flexibilização, precarização e terceirização. Para tanto, convém elucidar que a abordagem da temática será desenvolvida sob o viés do princípio da dignidade humana e da proteção ao hipossuficiente.

\footnotetext{
${ }^{2}$ Os dados estatísticos sobre desemprego e desigualdade social são a comprovação da difícil situação dos trabalhadores na sociedade pós-industrial.
} 


\section{DO FORDISMO-TAYLORISMO AO TOYTISMO}

Para a compreensão mais adequada da atual forma de organização produtiva, torna-se imperioso tratar do paradigma anterior de organização, ou seja, o fordismo-taylorismo, e sua crise, para, adiante, identificar e caracterizar o novo parâmetro de organização produtiva: o toytismo.

No início do Século XX, Frederick Taylor reinventa a organização do processo produtivo capitalista, com objetivo de extrair o maior aproveitamento possível da força de trabalho. Fundado em um ambiente produtivo mecanizado, com estudos dos tempos e movimentos realizados pelos trabalhadores, bem como a seleção, treinamento e organização dos empregados, basicamente, em dois setores: chefia, a que competia a fiscalização, organização e criação do processo produtivo, restrita ao número pequeno de trabalhadores com grande qualificação; execução, a que competiam as atividades repetitivas, braçais e de operação do maquinário, destinada a grande maioria dos trabalhadores com pouca qualificação.

Em 1913, Henry Ford inventa a produção padronizada, fundada na organização verticalizada, na qual a fábrica englobava todo o processo produtivo, desde do tratamento da matéria prima até detalhes finais do produto, incluindo, como na Ford, a própria comercialização. Era implementada em um processo mecânico (esteira ou linha de montagem) que fragmentava as funções desenvolvidas pelos trabalhadores, os quais eram encarregados individualmente de simples e repetitivas atividades. Dessa forma, obteve-se uma imensa economia, tanto com a redução de custos, com o aumento de produtividade, além da diminuição da resistência do trabalhador, em face do tempo imposto pela máquina e pela forma organizativa da produção.

O século $X X$ foi demarcado pelo modelo fordista e taylorista na forma de organização e produção das mercadorias. Consistia na organização do processo produtivo de massas de produtos homogêneos, operando através de grandes linhas de montagem. Ou seja, o fordismo agrega ao processo produtivo a noção de produção em série. De outro lado, o controle do tempo e dos movimentos dos operários no processo produtivo são resultados das idéias e estudos de Taylor. Ricardo Antunes disseca o modo fordista e taylorista, da seguinte forma: 
Pela existência de trabalho parcelar e pela fragmentação das funções; pela separação entre a elaboração e execução no processo de trabalho; pela existência de unidades fabris concentradas e verticalizadas e pela constituição/consolidação do operário em massa, do trabalhador coletivo fabril, entre outras dimensões (ANTUNES, 2000, p.25)

Destarte, o fordismo-taylorismo pautava-se na generalização/ homogeneização da execução do trabalho. Conseqüentemente, necessitava de um contingente imenso de trabalhadores realizando funções repetitivas, mecânicas e simples, desprestigiando a especialização técnica e/ou a habilidade individual.

Sustenta Boaventura de Sousa Santos que este modelo organizativo ampliou-se para além do processo produtivo, constituindo os elementos necessários para a formação de uma cultura de massa que, refinada ideologicamente conforma o que chamamos de consumismo. "Este forma de poder consiste no processo pelo qual a satisfação das necessidades por vida do mercado se transforma numa dependência em relação a necessidades que só existem como antecipações do consumo mercantil" (SANTOS, 1999, p. 312). Portanto, o fordismo e o taylorismo podem ser considerados como fundamentos de uma sociedade de massas com padrões homogeinizantes.

O fordismo/taylorismo teve seu desenvolvimento associado à expansão capitalista mundial, com grande ascensão durante o Estado do Bem Estar Social. No entanto, com as crises de 1960/70, o Capitalismo ingressa em mais uma metamorfose, sob viés do programa neoliberal de redução do Estado e da atividade produtiva. Transfere o seu eixo da produção industrial para o segmento de serviços, como também prefere obter lucros na especulação financeira, principalmente nos serviços das dívidas de países. Neste contexto de reorganização do Capitalismo, o mundo do trabalho também foi significativamente transformado.

A década de oitenta/noventa do século passado representou a ruptura com o fordismo/taylorismo. A automação, robótica e microeletrônica inseriram-se profundamente no meio produtivo, acarretando grandes mudanças nas relações de trabalho e no próprio sistema produtivo, inclusive considerando-se como a Terceira Revolução Industrial. Novos processos de trabalho emergem, situados em um novo paradigma. O padrão generalizante de produção, que caracterizou o fordismo, vem sendo substituído por formas produtivas mais flexíveis, individualizadas e desregulamentadas. 
Sugere Ricardo Antunes que o toyotismo "pode ser entendido como uma forma de organização do trabalho que nasce a partir da fábrica Toyota, no Japão, e que vem se expandindo pelo Ocidente capitalista, tanto nos países avançados quanto naqueles que se encontram subordinados" (2000, p. 181). Em sua essência, o toyotismo ampara-se no contexto da complexidade-diferenciação pós-moderna, para constituir-se um novo paradigma no processo produtivo.

É caracterizado por ter sua produção vinculada à demanda, desenvolvimento de produtos diferenciados, adequados aos interesses e necessidades do adquirente, resultado de ação em equipe de técnicos com multifunções e especialidades. Complementa Ricardo Antunes:

Temo como princípio o just in time, o melhor aproveitamento possível do tempo de produção e funciona segundo o sistema kanban, placas ou senhas de comando para reposição de peças e de estoque que, no toyotismo, devem ser mínimos. Enquanto na fábrica fordista cerca de $75 \%$ era produzido no seu interior, na fábrica toyotista somente cerca de $25 \%$ é produzido no seu interior. Ela horizontaliza o processo produtivo e transfere a terceiros grande parte do que anteriormente era produzido dentro dela (ANTUNES, 2000, p. 181/182)

De outro lado, não há mais parcelamento do trabalho como na linha de montagem fordista, mas trabalho realizado em equipes aptas, com flexibilidade na organização do trabalho e maquinário multifuncional, para produzir produtos diferenciados e individualizados. Ocorre, então, uma mudança no perfil do trabalhador. Anteriormente necessitava-se de trabalhadores sem especialização ou conhecimentos especiais para realização de tarefas simples e repetitivas. Com o modelo da Toyota, o trabalhador assume um perfil polivalente, isto é, para atender as demandas individualizadas do mercado, o trabalhador deve possuir relativa especialização ou conhecimento técnico e ter a capacidade de realizar atividades distintas e com máquinas diferenciadas.

O modelo da Toyota engendra uma nova organização do processo produtivo, marcada pela qualidade total do produto produzido. Frise-se que a noção de qualidade total não se refere à qualidade do resultado, mas sim do próprio processo produtivo, ou seja, almeja o aumento da produtividade. Acrescenta, também, uma diminuição do âmbito produtivo da empresa, com delegação de funções a terceiros, como a produção de componente ou serviço integrante do processo produtivo. No fordismo, o processo produtivo é vertical e concentrado na 
mesma empresa, no toyotismo é horizontalizado e difuso. Assim, o toyotismo perfaz uma reegenheria produtiva com incremento da terceirização e de precarização de condições trabalho, além do trabalho temporário.

Os avanços tecnológicos, além da colaboração com o modelo toyotista, têm, cada vez mais, em escala geométrica, transformado-se na própria força produtiva. Isto é, os avanços tecnológicos têm dispensado a atividade humana. Verifica-se, então, o fenômeno do desemprego estrutural, que extirpa postos de trabalho e funções em favor da automação da atividade laboral ou, mesmo, da própria desnecessidade da função, em face de novas técnicas produtivas.

Há um novo parâmetro na produção industrial, a revolução tecnológica confere à ciência e à tecnologia o papel de força produtiva. Mais precisamente, a tecnociência tornou-se agente da própria acumulação do capital, implicando em enorme acréscimo da produtividade do trabalho humano. Esta revolução consiste, em essência, na difusão e utilização de mecanismos/processos controlados pela informática, com capacidade de programar todo o processo de automação. A centralidade deste processo está na substituição da eletromecânica pela eletrônica como base do processo de automação, ou seja, o processo produtivo tem, então, como eixo a tecnologia de informação.

Com o desemprego estrutural, vivenciamos a diminuição do trabalho produtivo, considerado como aquele dispendioso de energia humana, sendo substituído pela automação. Tem-se, desta forma, a assunção do trabalho imaterial, compreendido como aquele inserto no campo intelectual e comunicativo, destinado a produção, armazenagem e organização do conhecimento e informações e relativo ao setor terciário de serviços. A definição de Ricardo Antunes explicita a questão:

o trabalho imaterial expressa a vigência da esfera informacional da forma-mercadoria: ele é expressão do conteúdo informacional da mercadoria; exprimindo as mutações do trabalho operário nas grandes empresas, e do setor de serviços, onde o trabalho manual está substituído pelo trabalho dotado de maior dimensão intelectual (2000, p. 162)

Todo o processo organizativo da produção, como visto, está em constante aperfeiçoamento, obtendo ganhos de produtividade em escala ascendente, por conseguinte, gerando mais riqueza. Particularmente, o toyotismo representa 0 sistema organizativo mais produtivo já visto, isto segundo os detentores dos meios de produção. Infelizmente, toda a melhoria nesses processos, especialmente o 
aumento de produtividade e riqueza, não tem, em contra-partida, assegurando aos trabalhadores melhores condições de trabalho ou mesmo salariais. Aliás, toda evolução da organização da produção que tem obtido aumento de produtividade não tem traduzido para o trabalhador sua contrapartida, isto é, melhoria nas condições de trabalho e vida.

\section{AS ESTRATÉGIAS DO PÓS-FORDISMO PARA AS RELAÇÕES DE TRABALHO}

Como visto no tópico anterior, o modelo de produção da Toyota no Japão tem ocupado a vanguarda das novas formas de produzir posteriores à crise do fordismo-taylorismo, embora não seja o único³.

Nas relações de trabalho, o pós-fordismo enseja alterações profundas nos contratos de trabalho, pois pretende aviltar as relações de trabalho e as conquistas obtidas no contexto do sindicalismo forte e do Estado do Bem-Estar-Social. Para tanto, atacar o contrato de trabalho em três sentidos: no interno, exigindo a flexibilização dos direitos e garantias dos empregados; no externo, retirando a proteção ou regulamentação da relação de trabalho, através da precarização; no misto, expulsando seus trabalhadores do quadro da empresa para relocá-los em empresas prestadoras de serviço, mediante a terceirização. Assim, analisaremos estas três estratégias.

A etimologia da palavra flexibilizar indica seu sentido como ato de vergar-se ou curvar-se perante algo ou alguém. No entanto, os defensores da flexibilização contextualizam seu sentido como apenas flexibilidade ou adaptação da norma, face à situação econômica mundial em crise e intensa concorrência. Então, a flexibilização preconiza a redução de vantagens e direitos, permitindo que o empregador, diminuindo custos, obtenha sucesso no cenário competitivo.

A luz de seus defensores, a flexibilização tem um propósito extremamente benéfico para a sociedade, uma vez que representa uma alternativa para a preservação dos empregos, ainda que com alterações in pejus no contrato de trabalho, em face da crise econômica, da intensa competitividade interna e externa e

\footnotetext{
${ }^{3}$ São exemplos o modelo Kanban utilizados nos Supermercados dos Estados Unidos de manutenção de pequenos estoques e reposição de produtos em observância às placas colocadas após a venda (kanban).
} 
dos impactos dos avanços tecnológicos. Ou seja, optam pela diminuição/retirada de direitos dos trabalhadores, com vistas a reduzir os custos da produção, que, segundo esta corrente de pensamento, permitirá a sobrevivência da empresa no mercado global. Para isto, concebem e defendem uma ampla liberdade sindical, na qual a autonomia privada coletiva deve prevalecer, principalmente quando estabelecer diminuição de direitos e vantagens individuais decorrentes de Lei ou do contrato individual

No entanto, a flexibilização tem servido à diminuição da proteção trabalhista, e também previdenciária, com fundamentos econômicos, em favor do barateamento da produção e aumento de lucros das empresas. Isto porque o que se têm observado que as empresas, mesmo com a redução dos direitos e conquistas, após um curto período, prosseguem dispensando seus empregados. Souto Maior assevera:

A teoria da flexibilização (que reflete mera intenção de reduzir os custos do trabalho) se
impõe, apresentando-se como moderna, embora tenha estado na própria origem paradoxal
das primeiras leis trabalhistas. Lembre-se que o conflito trabalhista foi identificado, desde
seus primórdios, como o choque de interesses distintos de empregados e empregadores: os
primeiros querendo trabalhar menos e ganhar mais; os últimos, querendo que os
trabalhadores trabalhem mais por menores salários" (2002, p. 1290)

A segunda estratégia é denominada comumente de desregulamentação, embora se adote, neste trabalho, por ser mais adequado, a expressão precarização (FREITAS, 2001). A precarização é, de fato, a eliminação do Direito do Trabalho, uma vez que "torna o contrato e as condições de trabalho mais frágeis (...) tornam as empresas mais livres para contratar e dispensar empregados (...) retiram do Estado atribuições relacionadas a proteção trabalhista e/ou previdenciária" (FREITAS; 2001, p. 6).

Considera-se a precarização uma postura mais extremada do que a flexibilização, porque pretende a retirada de regulamentação, delegando para a autonomia privada o estabelecimento das condições de trabalho e sua retribuição. É a anomia no dizer de Romita (2000), ou seja, inexistência de regulação legal de caráter protetivo para o trabalho que, assim sendo, deverá, individual ou coletivamente, ajustar com o empregador os termos do contrato de trabalho. A título de diferenciação, a flexibilização reside na seara interna do contrato, realizando 
redução/adaptação dentro dos termos estabelecidos no contrato de emprego, enquanto que a precarização age na seara externa do contrato, uma vez que não assegura qualquer direito ou vantagem estabelecida no contrato, por isso é chamado de contrato precário.

A última estratégia é a terceirização, originada no toyotismo, que se fundamenta em argumentos de ordem técnica que sustentam uma maior e melhor produtividade, através desta forma organizativa da produção. Alega-se que a transferência de funções e atividades não relacionadas com a atividade-fim (denominadas de atividades-meio) resulta em melhor qualidade, porque esta atividade será delegada a uma empresa terceirizada tecnicamente especializada para a função e, conseqüentemente, importará em maior produtividade, eis que a empresa que terceiriza concentrará suas energias na atividade fim. Argumenta-se que com a terceirização há diminuição de custos e, em decorrência, diminuição dos preços, favorecendo o consumo.

Nesses termos, a terceirização caracteriza-se pela presença de um intermediário entre o trabalhador e a empresa que usufrui dos serviços deste. Constata-se, portanto, uma dissociação da figura do empregador, posto que existe um que admite e assalaria e outro que dirige os serviços. É este o conceito de Maurício Godinho Delgado:

Para o Direito do Trabalho terceirização é fenômeno pelo qual se dissocia a relação econômica de trabalho da relação justrabalhista que the seria correspondente. Por tal fenômeno insere-se o trabalhador no processo produtivo do tomador de serviços sem que se estendam a esse os laços trabalhistas, que se preservam fixados com uma entidade interveniente. A terceirização provoca uma relação de trabalho trilateral em face da contratação de força de trabalho no mercado capitalista: o obreiro, prestador de serviços, que realiza as atividades materiais e intelectuais junto à empresa tomadora de serviços; a empresa terceirizante, que contrata este obreiro, firmando com ele os vínculos jurídicos trabalhistas pertinentes; a empresa tomadora do serviço, que recebe a prestação do labor, mas não assume a posição clássica de empregadora desse trabalhador envolvido. (DELGADO; 2003, p. 424)

Márcio Túlio Viana relata que, em função da competitividade decorrente da globalização, a terceirização se torna uma necessidade imposta por esse sistema, apontando como caminho para a redução de custos ao expulsar da empresa o 
controle de etapas do processo produtivo. Márcio Túlio Viana afirma que no Direito comparado:

Entre os economistas, essa prática também é conhecida como outsourcing ou putting-out. No Direito Comparado em geral, se usa o termo subcontratação. A empresa joga para suas parceiras algumas das - mesmo todas as - as etapas de seu ciclo produtivo, enxugando-se. (VIANA; 2003, p. 776)

É preciso desvelar que a terceirização compreende uma estratégia externalizante. Com efeito, repassa para uma terceira a responsabilidade por uma etapa do processo produtivo, e, por conseqüência, a responsabilidade pelas obrigações trabalhistas e previdenciárias. Registre-se que também possibilita um regime de diferenciação entre os empregados diretos e os terceirizados, confirmada pela distinta representação sindical e inclusive com parâmetros salariais incompatíveis. Propicia, então, o surgimento de pequenas empresas ao redor da tomadora, sem idoneidade, incorrendo, geralmente, no inadimplemento dos créditos trabalhistas. "Mas existe outro detalhe importante. Na verdade, como vimos, o que a empresa faz é um duplo movimento. Ela expulsa o trabalhador protegido e o retorna sem proteção, seja por meio de terceirizações internas, como por meio das externas" (VIANA; 2003, p. 785)

Márcio Túlio Viana relata a seguinte pesquisa:

O estudo do Dieese, em 1999, envolvendo 40 empresas terceirizadas do ABC, apontavam: em $72,5 \%$ dos casos, benefícios sociais inferiores; e em $67,5 \%$ níveis salariais mais baixos. As jornadas eram mais extensas e as condições de saúde e segurança mais precárias. (2003; p. 781)

Em verdade, o fenômeno da externalização ou out-sourcing representa o intento do paradigma pós-fordista em evair-se das obrigações trabalhistas, a partir de novas formas de trabalho. Washginton da Trindade leciona que

Tais formas novas apontam para o fenômeno do out-sourcing, da externalização do trabalho, que se desvincula do trabalhador como peça do mecanismo patronal, visando na opinião dos doutores das humanas, a um só tempo, abolir o contrato a tempo integral, transformar $\mathrm{o}$ trabalhador em empresário, livrando-se dos inconvenientes do poder hierárquico e das inarredáveis obrigações sociais. (TRINDADE; 1998, p.18) 
Além destes problemas, a organização toyotista propicia o enfraquecimento da categoria e dos sindicatos de trabalhadores, pois dificulta a organização associativa. Há, também, uma dispersão da categoria de prestadores de serviços que dificulta a formação ou o fortalecimento de um sindicato que possa representar e pleitear melhoria nas condições de trabalho. Portanto, o modelo terceirizante e toyotista é nitidamente anti-sindical e prejudicial ao trabalhador, criado com o intuito de reduzir salários e enfraquecer os sindicatos. Nesse sentido, "a quebra do movimento operário se explica pela terceirização. Foi ela a arma secreta que o capitalismo (re)descobriu ou (re)inventou. Ela permite resolver a contradição entre a necessidade do trabalho coletivo e a possibilidade de resistência coletiva" (VIANA; 2003, p. 789).

A organização toyotista, no intento do máximo aproveitamento, reduz não só o estoque de peças, mas também o estoque de mão de obra, ao ponto de se considerar que "a fabrica tende a se tornar uma mera gerenciadora de mão de obra, num movimento inverso ao dos tempos fordistas. É que o que alguns vêm chamando de empresa vazia." (VIANA; 2003, p. 781).

\section{5. (IN)CONCLUSÃO}

A título de (in)conclusão, o mundo do trabalho pode ser atualmente caracterizado pela heterogeinização das formas de trabalho, particularmente com o decréscimo do trabalho classicamente assalariado, o emprego. Frise-se que a redução do emprego em favor de relações supostamente autônomas ou precarizadas, importa em exclusão de um imenso contingente de trabalhadores do sistema protetivo trabalhista, social e previdenciário. Esse novo mundo do trabalho criou, conseqüentemente, uma classe trabalhadora diferenciada do operariado fordista, assim definida por Antunes:

Essas mutações criaram, portanto, uma classe trabalhadora mais heterogênea, mais fragmentada e mais complexificada, dividida em trabalhadores qualificados e desqualificados do mercado formal e informal, jovens e velhos, homens e mulheres, estáveis e precários, imigrantes e nacionais, brancos e negros, etc., sem falar nas divisões que decorrem da inserção diferenciada dos países e de seus trabalhadores na nova divisão internacional do trabalho. (2000, p. 184) 
Assim, a heterogeinização implica a conformação de um mundo do trabalho plural, diferenciado, multifacetado e difuso. Vejamos a referida pluralidade nas possibilidades de trabalho no mundo contemporâneo:

Encontramos entre essas formas o trabalho temporário, o estágio, o trabalho em tempo parcial, autônomos, falsos autônomos, cooperados, trabalhadores organizados em forma empresarial, eventuais, avulsos, free-lancers, domésticos, diaristas, horistas, empreiteiros, subempreiteiros, trabalhadores com emprego partilhado (job sharing), trabalhadores a distancia, contrato de solidariedade externo ou expansivo, trabalhadores engajados em contratos civis, etc. (CARELLI; 2004, p. 17)

Com acerto, registra Rodrigo Carelli dois importantes problemas caracterizadores destas formas multifacetadas e heterogêneas de trabalho:

Corresponde à lógica de erosão das características típicas do espaço tradicional da empresa, ocorrem dois problemas: a opacidade do empregador real e falta de tipicidade, ou seja, desconexão entre o conceito de trabalho subordinado, levando ambos os problemas à inefetividade das normas trabalhistas infraconstitucionais, e mesmo dos direitos sociais constitucionalmente garantidos. (CARELLI; 2004, p. 17)

Pode-se, portanto, analogicamente dividir o mundo do trabalho em dois grupos de trabalhadores: os incluídos, com perfil de profissional especializado e/ou detentor de técnica, contratado nos termos da legislação trabalhista e previdenciária, embora representem um pequeno contingente no total dos trabalhadores; os excluídos, os demais não englobados no tipo anterior e que não se configuram como autônomos, por não ter perfil especializado, sendo submetidos a contratações precárias, ou mesmo a uma relação civil de prestação de serviços, na qual prevalece a hiper-exploração, em razão de que cabe aos trabalhadores todo o risco e custo da atividade, não obstante seja da empresa contratante a possibilidade de fixação da retribuição. O modelo toyotista pretende, então, "em vez de incluir, excluir empregados, direitos, políticas sociais, etapas do processo produtivo." (VIANA; 2003, p. 779).

Com efeito, o diagnóstico da situação laboral contemporânea repete os dilemas de surgimento do Direito do Trabalho: a excessiva exploração do trabalhador, seja através de formas distintas da relação de emprego (precarização), seja através da redução dos direitos e obrigações trabalhistas (flexibilização) ou mesmo pela sublocação (terceirização). Identifica-se nas relações laborais uma 
recorrente tensão entre a defesa da liberdade - mediante redução a intervenção protecionista juslaboralista, e a afirmação da defesa da igualdade e da regulação por meio da tutela protetiva do Direito do Trabalho. Washington da Trindade arremata:

\begin{abstract}
É provável que a aceleração imprimida aos fenômenos sociais, principalmente pela revolução tecnológica, justifique as flutuações dos grupos que se inclinam ora pela motivação de mais liberdade, ora pelo sistema dos freios e contrapesos, na acomodação pacífica dos interesses em conflito (TRINDADE; 1995, p. 78)
\end{abstract}

Portanto, os reflexos do pós-fordismo nas relações de trabalho indicam o surgimento de novas formas contratuais distintas da relação empregatícia. A parassubordinação é a exemplar, posto que, sendo proveniente da descaracterização da subordinação clássica através da sua diluição, é definida como a prestação de serviço externalizada e mais em observância aos modos de produzir e fazer determinados pela empresa (TRINDADE; 1998).

Trata-se da, transcrevendo as sintéticas e exatas palavras do Prof. Washington da Trindade, "passagem do contrato de trabalho subordinado (contract of employment) ao contrato de atividade (contract of work) como figura central de um Direito do Trabalho renovado". (TRINDADE; 1998, p. 15)

Em consonância com uma postura protecionista, sustenta-se que o Direito do Trabalho urge ser repensado, com o objetivo de conferir maior efetividade na proteção aos empregados e ampliar-se para ofertar proteção aos trabalhadores heterogêneos e diferenciados, mesmo que, para estes últimos, se instala uma tutela menor do que para os empregados. Considerando que a ontologia do juslaboralismo se adstringe ao protecionismo, os princípios do Direito do Trabalho devem assumir dimensão mais ampla e compatível com uma sociedade em transição para o pósfordismo e para a pós-modernidade. Em defesa dos princípios, assinala Luiz Otávio Renault:

Mesmo que se admita que alguns institutos do Direito do Trabalho estejam ultrapassados, seus princípios permanecem sólidos e aptos a proporcionar as mudanças exigidas pelo novo modelo econômico, desde que se insira o homem no centro da vida sócio-econômicocultural. (RENAULT; 2004, p 85) 
Precisa-se, então, resgatar a essência do Direito Laboral advinda de sua gênese. $\mathrm{Na}$ análise da origem do Direito Trabalho, pode-se encontrar seu sentido e sua ontologia, que teve surgimento a partir das ações e reivindicações da coletividade dos trabalhadores. Proveniente, diretamente, do mundo fático, o Direito do Trabalho nasceu com eminência e particularidade na seara jurídica. No contexto em que a igualdade jurídica era basilar, o Direito do Trabalho afirma a desigualdade como fundamento de sua existência, inferindo a necessidade da proteção do hipossuficiente. No dizer de Arnaldo Sussekind (2003) "é o produto da reação verificada no século XIX contra a exploração dos assalariados por empresários".

A atual realidade repete os dilemas de surgimento do Direito do Trabalho: a excessiva exploração do trabalhador através de formas distintas da relação de emprego. É mister, então, repensar o Direito do Trabalho para encontrar novos parâmetros e fundamentos que justifiquem sua existência, uma vez que o discurso liberalizante sugere, em contra-senso, a sua redução ou o seu fim.

Repensar o Direito do Trabalho, implica compreender que as inovações tecnológicas e a reestruturação produtiva forjaram uma crise no conceito clássico de subordinação. Diga-se, de passagem, que a fuga à subordinação tradicional é notadamente um movimento intencional, pois procura fugir da tutela trabalhista da relação empregatícia, visando a redução das despesas. "Forçado a autonomia, o trabalhador não chega a ser autônomo de fato: mesmo em seu micro-negócio, carrega um estigma de desempregado. Aliás, muitas vezes, continua a ser um verdadeiro empregado, pois a relação de dependência não termina: apenas se desloca e se traveste" (VIANA; 2004, p. 185). Márcio Túlio Viana continua:

O conceito de subordinação, que era unívoco e se ampliava sempre, alcançando um número crescente de pessoas, tende hoje a se partir em dois: de um lado, os realmente dependentes, aos quais se aplicam as velhas garantias; de outro, os parassubordinados, para os quais se procuram soluções a meio caminho, como acontece com certo projeto de lei. Com isso, de forma inteligente, difunde-se a idéia de que está havendo mais proteção, quando, na verdade, quebra-se a marcha expansiva do Direito do Trabalho: os trabalhadores fronteiriços, que seriam tendencialmente considerados empregados, passam a constituir uma nova (sub)categoria jurídica. (VIANA; 2004, p. 173)

Em termos (in)conclusivos, defende-se que a manutenção da tutela do empregado e a invenção de novas tutelas para os trabalhadores heterogêneos e diferenciados representam um caminho de saída da crise do Direito do Trabalho, 
que reafirma a proteção e coaduna com a dignidade. Todavia, a ontologia juslaborista - que inspira a expansão do Direito do Trabalho, indica que a proteção ao trabalho é a própria proteção do homem e de sua dignidade e que, portanto, não deve se restringir a somente uma categoria de trabalhadores, os empregados. Enfim, assegurar proteção ao todo e qualquer tipo de trabalho é assegurar proteção ao homem e sua dignidade, valor maior da Constituição e da própria sociedade.

\section{BIBLIOGRAFIA}

ANTUNES, Ricardo. Adeus ao Trabalho? 7ạ. São Paulo: Cortez, Universidade Estadual de Campinas, 2003;

BRASIL. Consolidação das Leis do Trabalho. Diário Oficial da República Federativa do Brasil, 1943;

CARELLI, Rodrigo Lacerda. Formas atípicas de trabalho. São Paulo: LTr, 2004;

DALLEGROVE NETO, José Afonso. Novos contornos da relação de emprego diante dos avanços tecnológicos. São Paulo: LTr, julho/2003;

DELGADO, Maurício Godinho. Curso de Direito do Trabalho. 2ª . São Paulo: LTr, 2003;

FREITAS, Carlos Eduardo. Precarização e Leis do Trabalho na era FHC. CUT. São Paulo: CUT, 2001;

MASI, Domenico De. Desenvolvimento sem Trabalho. São Paulo: Ed Esfera, 1999;

OLIVEIRA, Murilo Carvalho Sampaio. Repensando o Direito do Trabalho. Jornal a Tarde. In Judiciárias. Salvador, 17 de outubro de 2004;

RENAULT, Luiz Otávio Linhares. O Direito do Trabalho? In PIMENTA, José Roberto Freire (org.). Direito do Trabalho: evolução, crise, perspectivas. São Paulo: LTr, 2004;

ROMITA, Arion Sayão. A flexibilização das leis do Trabalho em debate: choque e correntes. In FILHO FRANCO, Georgenor de Souza (org). Presente e Futuro nas Relações de Trabalho. São Paulo: LTr, 2000;

SOARES FILHO, José. A crise do Direito do Trabalho em face da globalização. São Paulo: LTr, outubro/2002;

SOUSA SANTOS, Boaventura de. Pela Mão de Alice: o social e o político na pós-modernidade. 6ª edição. São Paulo: Cortez Editora, 1999

SOUTO MAIOR, Jorge Luis. Pai afasta de mim este cálice. São Paulo: LTr, dez/2003; 
TRINDADE, Washigton Luiz. A avulsidade e o declínio do salariado. Revista T\& D. São Paulo: 1998;

A desregulamentação entre a liberdade e a lei. Revista T\& D. São Paulo: 1995;

VIANA, Márcio Túlio. Tercerização e sindicato: um enfoque para além do jurídico. São Paulo: LTr, julho/2002;

Proteção Social do Trabalhador no Mundo Globalizado. In PIMENTA, José Roberto Freire (org.). Direito do Trabalho: evolução, crise, perspectivas. São Paulo: LTr, 2004. 